\title{
Dependencies and autonomy in research performance: examining nanoscience and nanotechnology in emerging countries
}

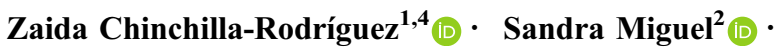 \\ Antonio Perianes-Rodríguez ${ }^{3}$ (D) Cassidy R. Sugimoto $^{4}$ (D)
}

Received: 28 February 2017/Published online: 21 January 2018

(C) The Author(s) 2018. This article is an open access publication

\begin{abstract}
International collaboration in the creation of knowledge is changing the structural stratification of science, with implications for science policy. Analyses of collaboration in developing and emergent countries are of particular significance because initiatives are often the result of "research-for-aid" arrangements, generally based on North-South asymmetries. However, collaboration for mutual benefit and excellence has gained increasing acceptance, with "partner" selection becoming a strategic priority to enhance one's own production. This article explores the capacity of BRIC and select Latin American countries in the generation of scientific knowledge and their visibility at the global level in the field of nanoscience and nanotechnology. The goal is to determine to what extent countries benefit from the role of their collaborators to heighten research performance in terms of citation; and how collaboration could help countries to leverage their competitiveness through the design of research and development agendas. The method relies on the decomposition of leadership, as well as its consideration in view of performance indicators such as normalized citation impact, scientific excellence, and
\end{abstract}

\footnotetext{
Zaida Chinchilla-Rodríguez

zaida.chinchilla@csic.es

Sandra Miguel

smiguel@fahce.unlp.edu.ar

Antonio Perianes-Rodríguez

aperiane@bib.uc3m.es
}

Cassidy R. Sugimoto

sugimoto@indiana.edu

1 Instituto de Políticas y Bienes Públicos, Consejo Superior de Investigaciones Científicas (IPPCSIC), C/Albasanz, 26-28, 28037 Madrid, Spain

2 Instituto de Investigaciones en Humanidades y Ciencias Sociales, IdIHCS (UNLP-CONICET), Universidad Nacional de La Plata, calle 51 e/124 y 125, 1925 Ensenada, Argentina

3 Departamento de Biblioteconomía y Documentación, Universidad Carlos III, C/Madrid, 128, 28903 Getafe, Spain

4 School of Informatics, Computing and Engineering, Indiana University, 919 E 10th St, Bloomington, IN 47408, USA 
technological impact. The results suggest that the growth of international collaboration should be interpreted as a positive aspect. Furthermore, a progressive internationalization of scientific activity concerned with local needs or topics of interest is found to have the capacity to determine research agendas whose interest would extend to communities far beyond, thereby contributing to the development of science at a national level.

Keywords Scientific collaboration · Research performance - Leadership · Latin America · BRICS · Nanoscience and nanotechnology

Mathematics Subject Classification 94 Information and communication · Circuit

JEL Classification D8 Information · Knowledge · Uncertainty

\section{Introduction}

The creation of new knowledge based on international collaboration implies structural changes affecting the stratification of science. The changing relationship between the geographical and intellectual dimensions of science has profound implications for the governance of science (Leydesdorff et al. 2013). A certain tension between national and international science is reflected in today's research evaluation models, where the criterion based on productivity and publication in peer-reviewed journals of international circulation can loom as a bias for the research agendas of the South with respect to the North (Sutz 2005). Factors conditioning the practice of science in "peripheral contexts" may include the selection of research topics, agenda, or criteria behind publication and evaluation (Vessuri 1984; Kreimer 2000, 2006).

Initiatives to promote and support research adopt different forms from one region to another, and may include technical assistance, local training, and support for the development of specific institutions, institutional partnering, or international agreements. For developing countries, initiatives are often the result of "research-for-aid" arrangements, generally based on North-South asymmetries (Bonfiglioli and Mari 2000). Over the years, however, collaboration for mutual benefit and excellence has gained increasing acceptance, with "partner" selection becoming a strategic priority to enhance one's own production. In this context, a key prerequisite for the design of regional collaboration policies is the determination of how developing partners attain higher research potential - that is, higher production and impact (Velho 2002; Miguel et al. 2015).

Relationships of scientific co-operation among countries and processes of internationalization can also be approached from the standpoint of academic dependence, understood as an unequal structure of output and dissemination of knowledge on the part of industrialized countries as opposed to peripheral ones (Beigel and Sabea 2014). Within this framework, the concept of autonomy has been broadly interpreted. Some authors hold that peripheral knowledge is the result of a "captive mind"; others demonstrate that a peripheral community may reduce its import of foreign knowledge and increase the local production of concepts or methods. In general, autonomy of science is mostly limited by the need to obtain funding and by the agendas of the organizations and nations that can provide it (Wagner et al. 2001). In this sense, the most scientifically and autonomous nations are those that historically have played an important role in investing and maintaining their expenditures in R\&D. These factors, inter alia, help them to create a solid scientific 
infrastructure and a high profile as attractive partners in obtaining funding and high-quality expertise (Chinchilla-Rodríguez et al. 2016b).

It is generally acknowledged that collaboration is an added value for increasing productivity and visibility (Gazni et al. 2012). Multi-country publication increases the chances that an article be more cited; and countries benefit from participation in multinational projects, which eventually leads to an improved citation factor (Glänzel 2001; Glänzel and De Lange 2002). Increasing international collaborations and developing mixed research teams also has a positive effect on the impact factor and the research quality of publications (Wagner et al. 2001). Nevertheless, the effects of collaboration do not always translate into benefits of similar magnitude (Persson 2010). Although collaboration can take many forms - collaborative projects, publications in common, informal contacts, interchange of researchers or fellows among different countries, and participation in conferences (Fernández et al. 1998; Guerrero-Bote et al. 2013)—authorship is generally used as a proxy for collaboration (Katz and Martin 1997; Glänzel 2001). However, examining collaboration alone is a weak determinant for the dependency of certain countries as collaboration alone fails to identify the leadership roles of various authorsand, thereby, countries.

To understand more fully the role of countries, lead authorship must be determined. Since most papers come from teams of scientists participating in domestic or international projects, we hold that the first author is the leader of the paper, along with the institution of country affiliation of this author. This operationalization is validated by two bodies of work. The first is that of Moya-Anegón et al. (2013) who find a strong relationship between first authorship and "corresponding author" and that of Lariviere et al. (2016) who find that first author is the strongest determinant to papers. By analyzing not only collaborative relationships, but also the leading role of each country provides an opportunity to more fully understand the dependencies of the scientific system. We may moreover determine the volume and impact of each country's scientific output, the breadth and scope of its networks of collaboration and, consequently, the national capacity for receiving or transmitting knowledge flows (Chinchilla-Rodríguez et al. 2010).

At present, the scientific field of nanoscience and nanotechnology (NST) has attracted the attention of policymakers worldwide, and several countries have included NST research programs in their agendas. The economic and social advances of NST affect sectors such as industry, health, the environment, and national security (Huang et al. 2011). This implies both challenges and opportunities for other countries at medium levels of development, to harness their capabilities and eventually benefit from commercial opportunities through targeted investments and strategic collaborations. The fast growth of NST is also reflected in the number of publications and patents entailing advancements in knowledge or industrial applications. Against this background, scientific benchmarking can be seen as a useful aid in decision-making about research performance-especially in the case of emerging countries - for two main reasons: the first is tied to the "models of academic dependency" outlined above, while the second would be the scarce representation of developing countries in the international arena, since most studies analyzing this field are focused on developed and emergent countries (Foladori 2006; Kay and Shapira 2009, 2011). 


\section{Objectives}

This article explores the capacity of BRICS and select Latin American countries in their contribution to the nanoscience and nanotechnology (NST) literature and its visibility at the global level. The novelty of the contribution lies in the decomposition of leadership, plus its combination with the results of performance indicators. We compare the normalized citation of all output and leading output, as well as scientific excellence, technological impact, and the trends across collaboration types.

A comparative benchmarking exercise is presented in this paper in order to characterize the size, impact, leadership, internationalization and the degree of excellence in terms of the set of papers included in the Top $10 \%$ highly cited publications of the main producers of NST output for BRICS and select Latin American countries during the period 20032013. Through the identification of different capacities of countries, we attempt to measure the scientific levels of autonomy or dependency based on internationalization and leadership and gauge the benefit rate in visibility and impact of scientific production in the field of NST. Evolutionary patterns of collaboration in conjunction to its normalized citation impact are shown to view strategies in associative partnerships and their impact. We also create visual networks of international collaboration in a given country (Argentina) to represent the difference between the citations received per type of output (total, in leadership, excellent, and excellent with leadership), and the associates with whom a country has greater potential and capacity to generate knowledge of high impact, as well as the differences existing in terms of visibility depending on the type of production analyzed.

In short, we wish to determine the benefits of collaborative efforts, and answer the following questions: (a) To what degree and in which ways do emerging countries contribute to the output of NST; (b) What benefits are derived through leadership roles on scientific output; (c) What is the relationship between autonomy/dependence and subsequent output/impact; (d) What changes can be observed over time; and e) How can dependency and autonomy be visualized for a single country?

International scientific collaboration is strategic for the scientific and economic growth of countries, particularly for developing and peripheral countries. BRICS countries are joined in an association to foster mutual development (Finardi and Buratti 2016). Within Latin America, specific initiatives to further cooperation among research teams in the member countries foster ongoing cooperation in higher academic or researcher mobility, in pursuit of regional integration and effective cooperation (The Ibero-American Research Area, Espacio Iberoamericano del Conocimiento [EIC]; CYTED 2010). Such initiatives are key in areas of research dedicated to economic and competitive growth, such as NST. Bibliometric analysis could be very helpful to monitor the scientific activities carried out and identify patterns and strategies that prove either beneficial or counterproductive in view of the expected and actual scientific impact.

\section{Data and methods}

\section{Data}

The data set was obtained from SCImago Journal \& Country Rank (SJR) (SCImago 2007) and SCImago Institutions Rankings (SIR) (SCImago 2015), based on the Scopus database. Field delineation for Nanoscience and Nanotechnology (NST) was drawn from SCImago, 
Table 1 List of indicators used in this study

\begin{tabular}{|c|c|c|}
\hline Label & Name & Description \\
\hline ndoc & Output & Number of documents by country in NST \\
\hline$\%$ world & Global contribution & Percent of contribution to total global NST output \\
\hline$\%$ lead & Leadership & $\begin{array}{l}\text { Percentage of a country's NST output on which the first (or } \\
\text { sole) author is from that country }\end{array}$ \\
\hline$\%$ non-coll & Non-collaborative & $\begin{array}{l}\text { Percentage of a country's NST output that is either single- } \\
\text { authored or in which all authors are from a single institution }\end{array}$ \\
\hline$\% \mathrm{IC}$ & International collaboration & $\begin{array}{l}\text { Percentage of a country's NST output that is collaboratively } \\
\text { authored with at least one other country (but without } \\
\text { national collaboration) }\end{array}$ \\
\hline$\% \mathrm{MC}$ & Mixed collaboration & $\begin{array}{l}\text { Percentage of a country's NST output that is collaboratively } \\
\text { authored with at least one other domestic collaborator and at } \\
\text { least one international author }\end{array}$ \\
\hline$\%$ & $\begin{array}{l}\text { Leadership in } \\
\text { collaboration }\end{array}$ & $\begin{array}{l}\text { Percentage of a country's collaborative NST output in which } \\
\text { an author from that country is first author }\end{array}$ \\
\hline$\% \mathrm{ICL}$ & $\begin{array}{l}\text { Leadership in international } \\
\text { collaboration }\end{array}$ & $\begin{array}{l}\text { Percentage of a country's internationally collaborative NST } \\
\text { output in which the lead author is from that country }\end{array}$ \\
\hline $\mathrm{NI}$ & $\begin{array}{l}\text { Field normalized citation } \\
\text { impact }\end{array}$ & $\begin{array}{l}\text { Average of relative citations (compared with the world } \\
\text { average for citations to documents within the same } \\
\text { document type, year, and category) received by each } \\
\text { country; values represent the relationship to the global } \\
\text { average of } 1\end{array}$ \\
\hline NIL & $\begin{array}{l}\text { Field normalized citation } \\
\text { impact in leadership }\end{array}$ & $\begin{array}{l}\text { Field normalized citation impact (see above) for only leading } \\
\text { (see above) output }\end{array}$ \\
\hline$\%$ exc & Excellence rate & $\begin{array}{l}\text { Percentage of output that is among the top } 10 \% \text { most highly } \\
\text { cited papers within a category }\end{array}$ \\
\hline$\%$ ewL & Excellence in leadership & $\begin{array}{l}\text { Percentage of excellent output in which the country is in a } \\
\text { leading role }\end{array}$ \\
\hline$\%$ eic & $\begin{array}{l}\text { Excellence in } \\
\text { collaboration }\end{array}$ & $\begin{array}{l}\text { Percentage of excellent output in which the country is not in a } \\
\text { leading role }\end{array}$ \\
\hline IK & Innovative knowledge & $\begin{array}{l}\text { Number of documents from a country cited in patents, based } \\
\text { on EPO-PATSTAT }\end{array}$ \\
\hline IKL & $\begin{array}{l}\text { Innovative knowledge in } \\
\text { leadership }\end{array}$ & $\begin{array}{l}\text { Number of documents from a country cited in patents in which } \\
\text { the country is in a leadership role }\end{array}$ \\
\hline TI & Technological impact & Percentage of NST output cited in patents \\
\hline TI_L & $\begin{array}{l}\text { Technological impact in } \\
\text { leadership }\end{array}$ & $\begin{array}{l}\text { Percentage of NST output cited in patents in which the } \\
\text { country is in a leading role }\end{array}$ \\
\hline BRCE & $\begin{array}{l}\text { Benefit rate of citation } \\
\text { impact }\end{array}$ & $\begin{array}{l}\text { The percent difference between a country's impact and impact } \\
\text { in leadership }\end{array}$ \\
\hline BRCNI & $\begin{array}{l}\text { Benefit rate of normalized } \\
\text { citation impact }\end{array}$ & $\begin{array}{l}\text { The percent difference between a country's normalized impact } \\
\text { and normalized impact in leadership }\end{array}$ \\
\hline BRCTI & $\begin{array}{l}\text { Benefit rate of } \\
\text { technological impact }\end{array}$ & $\begin{array}{l}\text { The percent difference between a country's technological } \\
\text { impact and technological impact in leadership }\end{array}$ \\
\hline BRCIK & $\begin{array}{l}\text { Benefit rate of innovative } \\
\text { knowledge }\end{array}$ & $\begin{array}{l}\text { The percent difference between a country's innovative } \\
\text { knowledge and innovative knowledge in leadership }\end{array}$ \\
\hline
\end{tabular}


which is generated using a combination of subject classification, citation-, and query-based approaches (Muñoz-Écija et al. 2013). At present, there are 91 journals, which represent NST in SCImago. ${ }^{1}$ SCImago uses all document types from Scopus for production indicators (e.g., output, leadership, collaboration), but only incorporates articles, reviews, and conference papers for the normalized indicators. For the years 2003-2013, there were 176,158 documents in the category of Nanoscience and Nanotechnology, representing $1.1 \%$ of all documents indexed in Scopus during those years. These were primarily articles (88\%), but also included conference papers $(9 \%)$, reviews $(3 \%)$ and a small fraction of other document types. Within this set, we focus our analysis on the 55,228 documents that contain at least one author affiliated with a BRICS country-that is, Brazil, Russia, India, China, and South Africa-and the nine Latin American countries with more than ten publications in NST during this time period (2003-2013).

\section{Indicators}

Table 1 provides the indicators used in this analysis. For the purpose of this paper (and drawing upon the work of Moya-Anegón et al. 2013), we use the corresponding author as a proxy for the leading author. Furthermore, we categorize documents into four exclusive authorship categories: (1) documents that are non-collaborative (which include multipleauthored papers where all authors are at the same institution), (2) documents that are the result of national collaborations (with domestic institutions), (3) documents that have multiple national collaborators as well as at least one international author, and (4) documents which have authors from at least two countries (but do not also contain domestic collaborations). One of the focal points of the analysis is the application of benefit indicators; that is, indicators which describe the degree to which a country benefits or suffers (as measured by citations) when it is not in a leading role. Specifically, it is the difference between the normalized citation, scientific excellence, and innovative knowledge for all output and leading output. If the value is low or negative, the country does not derive benefits from collaborations when it is not in a leading role. It should be advised that many of these indicators are size-dependent and should be interpreted within the contextual frame of the overall production of a given country.

Countries were analyzed according to their income level group, as defined by the World Bank (2015), based on estimates of gross national income (GNI) per capita for the previous year. Visualizations were constructed using Pajek software (Batagelj and Mrvar 1997), based on an adaptation of the method presented in previous research (Chinchilla-Rodríguez 2005; Chinchilla-Rodríguez et al. 2010).

\section{Results}

Among the 176,158 documents in the Nanoscience and Nanotechnology category, nearly a third $(n=55,228 ; 31 \%$ ) were produced by BRICS countries-producing in the aggregate slightly more than the US production in this area $(n=51,838)$ (Table 2$)$. Among the BRICS countries, China produced the largest output—much more than a fifth of all NST output. India was a far second among BRICS countries, with only 5\%, followed by Russia, Brazil, and South Africa, who each produced around $1 \%$ of the global output. In the

\footnotetext{
1 This list can be accessed here: http://www.scimagojr.com/journalrank.php?category=2509\&year=2013.
} 


\begin{tabular}{|c|c|c|c|c|c|c|c|c|c|c|c|c|c|c|c|}
\hline & $\frac{v}{\infty}$ & $\stackrel{\circ}{\mathrm{I}}$ & $\stackrel{9}{=}$ & $\vec{n}$ & Эे & $\stackrel{m}{=}$ & $\underset{\infty}{\stackrel{\infty}{\infty}}$ & $\stackrel{\infty}{\tilde{\lambda}}$ & & $\stackrel{\dot{\Phi}}{\circ}$ & $\stackrel{m}{6}$ & $\begin{array}{l}\stackrel{\circ}{\dot{f}} \\
\dot{f}\end{array}$ & & & 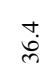 \\
\hline & E & $\stackrel{n}{-}$ & $\stackrel{m}{-}$ & $\ddot{o}$ & $\hat{0}$ & 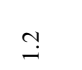 & $\hat{o}$ & $\stackrel{?}{\sim}$ & & $\stackrel{\circ}{-}$ & $\stackrel{\vartheta}{\dot{r}}$ & $\stackrel{m}{i}$ & & & $\stackrel{\circ}{-}$ \\
\hline & $F$ & $\cong$ & $\stackrel{ \pm}{-}$ & $\stackrel{+}{-}$ & $\stackrel{\circ}{-}$ & $\stackrel{ \pm}{-}$ & $\stackrel{m}{\sim}$ & $\because$ & $\stackrel{t}{0}$ & $\overrightarrow{\text { i }}$ & 9 & $\stackrel{m}{?}$ & & $m_{\infty}^{\infty}$ & $\stackrel{ \pm}{-}$ \\
\hline & $\underline{\underline{ }}$ & $\frac{0}{n}$ & $\bar{\Xi}$ & ஓ & in & $\bar{\sim}$ & $r$ & in & & $\mathrm{N}$ & $\sim$ & - & & & $\stackrel{\infty}{m}$ \\
\hline & $\mathscr{\Xi}$ & $\overrightarrow{0}$ & ఏ్ల & ช్ & $=$ & 尺 & $\stackrel{\infty}{\sim}$ & $a$ & - & 0 & $\sim$ & - & & - & $\ddot{\theta}$ \\
\hline & 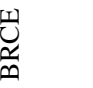 & $\stackrel{\dot{a}}{\mathrm{i}}$ & बे & 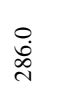 & $\stackrel{\infty}{\stackrel{\infty}{N}}$ & હ̃ & $\stackrel{9}{\underline{\Sigma}}$ & $\stackrel{\vec{n}}{\stackrel{2}{2}}$ & & $\begin{array}{l}\infty \\
\ddot{q} \\
\stackrel{\sigma}{\sigma}\end{array}$ & & $\stackrel{1}{2}$ & & $\overrightarrow{8}$ & $\stackrel{m}{I}$ \\
\hline & of $\frac{0}{2}$ & $\stackrel{+}{i}$ & $\exists$ & $\stackrel{\oplus}{-}$ & $\stackrel{+}{+}$ & $\stackrel{9}{-}$ & $\underset{\sim}{\stackrel{\circ}{i}}$ & $m$ & $\dot{\delta}$ & $\stackrel{+}{i}$ & & $\ddot{n}$ & & $m_{\infty}^{\infty}$ & 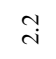 \\
\hline & $\therefore \frac{3}{3}$ & 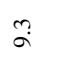 & $\vec{m}$ & $\tilde{n}$ & $\stackrel{\circ}{i}$ & $\stackrel{\infty}{-}$ & $\because$ & הี & $\stackrel{\circ}{\circ}$ & $n$ & & $\stackrel{m}{\longrightarrow}$ & & $\stackrel{m}{\infty}$ & $\stackrel{\infty}{\rightarrow}$ \\
\hline & or & $\stackrel{\Xi}{=}$ & $\stackrel{\infty}{+}$ & $\stackrel{9}{-}$ & ţे & $\hat{r}$ & $\stackrel{\sim}{+}$ & $n$ & $\hat{\sigma}$ & $\vec{i}$ & & $\stackrel{\infty}{\dot{m}}$ & & $\hat{\sigma}$ & $\stackrel{\circ}{\stackrel{f}{f}}$ \\
\hline & $\sum_{\frac{\infty}{\infty}}$ & $\begin{array}{l}\dot{0} \\
\dot{m}\end{array}$ & $\vec{\infty}$ & $\begin{array}{l}n \\
\text { İ }\end{array}$ & $\ddot{m}$ & $\vec{n}$ & $\begin{array}{l}0 \\
\text { ì }\end{array}$ & $\breve{6}$ & $\begin{array}{l}\infty \\
\dot{q} \\
\dot{q}\end{array}$ & $\stackrel{\circ}{\circ}$ & సี & $\hat{\grave{i}}$ & $\stackrel{n}{ \pm}$ & ָָ & त्. \\
\hline & 主 & 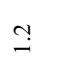 & $\stackrel{\circ}{0}$ & กั & $n$ & $n$ & $\stackrel{t}{0}$ & $\stackrel{0}{\circ}$ & ชี & ț & m. & $n$ & $\stackrel{\circ}{\circ}$ & 9 & $n$ \\
\hline & $\bar{z}$ & $\stackrel{\circ}{-}$ & $\hat{o}$ & $\stackrel{t}{0}$ & $\stackrel{0}{0}$ & $\stackrel{0}{0}$ & $\stackrel{\circ}{\circ}$ & $\hat{o}$ & $\stackrel{t}{0}$ & $\stackrel{0}{0}$ & $\stackrel{m}{0}$ & $\stackrel{\circ}{\circ}$ & $\hat{\circ}$ & $\stackrel{n}{-}$ & $\stackrel{0}{\circ}$ \\
\hline & \& & 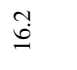 & $\stackrel{0}{\dot{D}}$ & 节 & 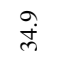 & $\stackrel{n}{d}$ & $\stackrel{m}{\stackrel{m}{0}}$ & $\underset{⿱ 亠 凶}{\dot{m}}$ & $\vec{n}$ & $\frac{0}{\dot{n}}$ & $\hat{\rho}$ & $\stackrel{N}{n}$ & & $\stackrel{\circ}{\dot{8}}$ & $\stackrel{+}{\circ}$ \\
\hline & \& & : & $\hat{i}$ & $\stackrel{\text { q̊ }}{q}$ & 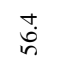 & $\stackrel{\circ}{\dot{\forall}}$ & $\vec{g}$ & ì. & ڤ્. & $\stackrel{\circ}{i}$ & $\stackrel{i}{\infty}$ & $\stackrel{+}{i}$ & ले & $\stackrel{8}{8}$ & 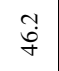 \\
\hline & Zֶ, & $\begin{array}{l}\text { के } \\
\dot{m}\end{array}$ & $\begin{array}{l}\infty \\
\infty \\
\dot{d}\end{array}$ & $\begin{array}{l}\vec{r} \\
\infty \\
\infty\end{array}$ & $\begin{array}{l}\text { na } \\
\text { ò }\end{array}$ & Iี & $\begin{array}{l}\tilde{\infty} \\
\infty \\
\infty\end{array}$ & $\frac{\circ}{\stackrel{m}{m}}$ & ֻิ & $\begin{array}{l}\dot{\sigma} \\
\ddot{g}\end{array}$ & 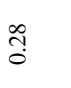 & $\begin{array}{l}+ \\
\text { in } \\
\infty\end{array}$ & $\stackrel{\infty}{-}$ & $\stackrel{8}{0}$ & $\underset{\stackrel{8}{0}}{\stackrel{\infty}{\infty}}$ \\
\hline & oீ & 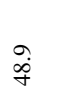 & $\ddot{\dot{m}}$ & $\stackrel{0}{n}$ & $\stackrel{m}{\infty}$ & $\stackrel{m}{q}$ & $\stackrel{\infty}{\stackrel{+}{q}}$ & $\hat{\vec{b}}$ & oे & oे & $\begin{array}{l}\stackrel{0}{0} \\
\stackrel{i}{i}\end{array}$ & $\stackrel{+}{\dot{b}}$ & $\stackrel{m}{\dot{\Xi}}$ & $\stackrel{\imath}{\sigma}$ & in \\
\hline & ஃீ & $\underset{\substack{\infty \\
\infty}}{\infty}$ & $\frac{n}{n}$ & $\stackrel{0}{\stackrel{+}{N}}$ & $\underset{0}{0}$ & 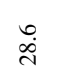 & $\stackrel{m}{m}$ & $\vec{n}$ & $\stackrel{\circ}{\mathrm{I}}$ & $\vec{m}$ & $\stackrel{\circ}{\mathrm{I}}$ & $\stackrel{\circ}{\infty}$ & $\stackrel{\sim}{\mathcal{F}}$ & $\because$ & $\stackrel{\vec{y}}{\ddot{y}}$ \\
\hline & 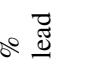 & $\frac{n}{\infty}$ & $\underset{\infty}{\stackrel{\infty}{\infty}}$ & $\stackrel{2}{n}$ & 8 & $\stackrel{9}{i}$ & $\vec{\sim}$ & $\begin{array}{l}\infty \\
\dot{0}\end{array}$ & $\hat{\theta}$ & $\ddot{8}$ & $\vec{\infty}$ & 芦 & 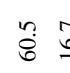 & $\hat{\sigma}$ & থֶ̊ \\
\hline & o & $\hat{i}$ & ĩ & $\stackrel{0}{i}$ & $\stackrel{0}{0}$ & $\stackrel{m}{-}$ & $\stackrel{\infty}{\circ}$ & 3 & $\overline{0}$ & $\overrightarrow{0}$ & $\overline{0}$ & $\stackrel{\circ}{\circ}$ & $\stackrel{\circ}{\circ}$ & $\stackrel{\circ}{\circ}$ & $\vec{i}$ \\
\hline & $\frac{o}{g}$ & 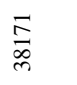 & $\bar{\sigma}$ & 岕 & $\stackrel{8}{9}$ & $\underset{\vec{N}}{\stackrel{\Delta}{N}}$ & 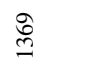 & ठ̊ & $\ddot{\sim}$ & $\stackrel{ }{\sim}$ & 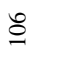 & $\curvearrowright$ & & & $\begin{array}{l}\vec{\infty} \\
\stackrel{\alpha}{+}\end{array}$ \\
\hline & 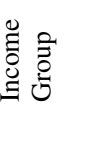 & 总 & 总 & 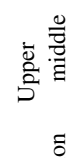 & 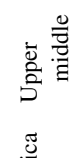 & 苛 & 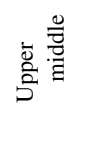 & 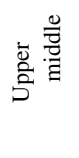 & 离莺 & 矛 & 离 & 总 & 咅 & 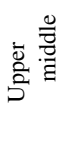 & \\
\hline & 蔦 & 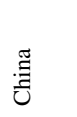 & $\stackrel{g}{g}$ & 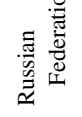 & 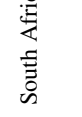 & 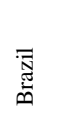 & 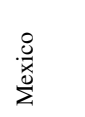 & 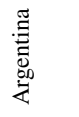 & $\begin{array}{l}\frac{\pi}{0} \\
\frac{0}{0} \\
\frac{0}{0}\end{array}$ & : & हొ & 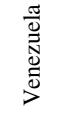 & & ت & $\underset{J}{U}$ \\
\hline
\end{tabular}


aggregate, the select Latin American countries produced slightly less than 3\% of the global output, with the highest output from Brazil and Mexico.

Variations can be observed in both collaboration and leadership. India is the least collaborative, with the majority of NST output classified as non-collaborative and the lowest proportion of internationally collaborative output. Russia and China demonstrated higher collaboration among domestic institutions. The highest levels of international collaboration were found in the Latin American countries and South Africa. However, there were strong differences in leadership role among these countries-while China and India led small proportions of internationally collaborative papers (16 and 13\%, respectively), this was the dominant role for Colombia, Chile, Cuba, Venezuela, Uruguay, and Peru. Russia and Brazil led about a quarter of their international output and South Africa led a third.

These results are not in accordance with those of Kay and Shapira (2009), whose focus, sources, and time-period of the study were somewhat different. Whereas they focus on Brazil, Argentina, Mexico, Chile and Uruguay, our aim is to show the regional picture of Latin America. Other differences reflect changes undergone in the last decade: for instance, the income level group (defined by the World Bank) for Chile and Uruguay, or the exponential growth in publishing recorded in Web of Science (Grieneisen 2010; Chen et al. 2013). Such growth is also reflected in the Scopus database, where the documents published show a nearly threefold growth of NST world share output; the main growth spurt is between 2007 and 2013, a period when it practically doubled (Chinchilla-Rodríguez et al. 2016b).

Discounting countries with very small output, China consistently led in citation indicators - in terms of normalized impact, excellence, and technological innovation-for both leading and non-leading output. China also had among the lowest benefit rates for all countries studied. Although most countries benefit to some degree (as shown by the positive value of the benefit rates), China seems to generate few advantages from taking a subordinate role on publications. These results are in stark contrast to Russia, which has the highest rates of benefit for impact and excellence-suggesting a level of dependency on foreign partners for high-impact publications. An analysis of the number of papers cited in patents in relation to the total papers published by each country in terms of technological impact (TI) (Moya-Anegón and Chinchilla-Rodríguez 2015) shows that the differences observed in citation-related indicators among the Russian Federation, Brazil, China and India tends to diminish in terms of technological impact, though Russia and South Africa continue to demonstrate higher dependence on foreign partnerships to generate high impact output.

To understand the roles in which each country generates the most benefit, we calculate the normalized impact, by type of collaboration, where a value of 1 represents the world average. For each country, we provide the normalized impact for all output (Fig. 1a) and leading output (Fig. 1b). For example, Brazil has a normalized impact equal to 0.61 in all papers and 0.53 in leading papers, which allows us to show the differences of the average of country and the different types of collaboration. In all cases, collaborative papers generate higher citations than non-collaborative papers and-for most countries-noncollaborative papers are below the world average. Domestic collaborations generate relatively high impact in China, whereas they tend to have negative effects for countries such as Cuba and Colombia. International gains are seen for all countries-though some tend to generate better citation results when they combine national and international partners (although this could be an artifact of team size). 

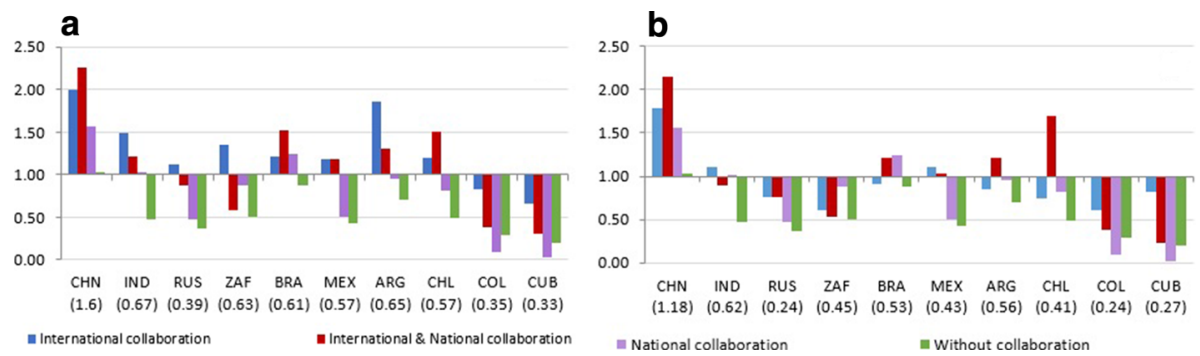

Fig. 1 Normalized citation by type of collaboration of all (a) and leading (b) outputs

Examining only leadership inverts some of these relationships (Fig. 1b). For example, Brazil receives, overall, the highest citations for mixed international and national collaboration; however, in the case of citation benefit, it seems to perform better on national publications than mixed and purely international collaborations. Argentina is another striking example, where the effect of international collaboration is completely reversed when examining only leading output. Russia and South Africa only obtain citations above the world average in international partnerships - these advantages disappear when authors from these countries are in leading roles. These findings suggest that there is no symmetry in citation advantage - to understand citation advantage, one must look not only at the composition of the collaboration, but also the authorship order.

\section{Autonomy and dependence on collaboration}

Figure 2 displays the benefit rate of normalized citation impact, scientific excellence, and technological impact. Differences in percentages of all and leading papers determine the benefit earned by each country when the given country does not lead collaboration. As noted earlier, the lower the benefit, the more autonomous the country; the higher the benefit, the more dependent the country is on foreign collaborations for citation gains. For instance, we find that China and India derive very little benefit in terms of citation or excellence and only moderate advantages for technological impact. However, China's citation rates exceed those of India. This displays the complicated notion of autonomyautonomy does not necessarily equate to higher or lower research performance. The inverse is also true. For example, Chile and Cuba both attain relatively high technological impact: for Chile, there is high dependency, for Cuba nearly total autonomy.
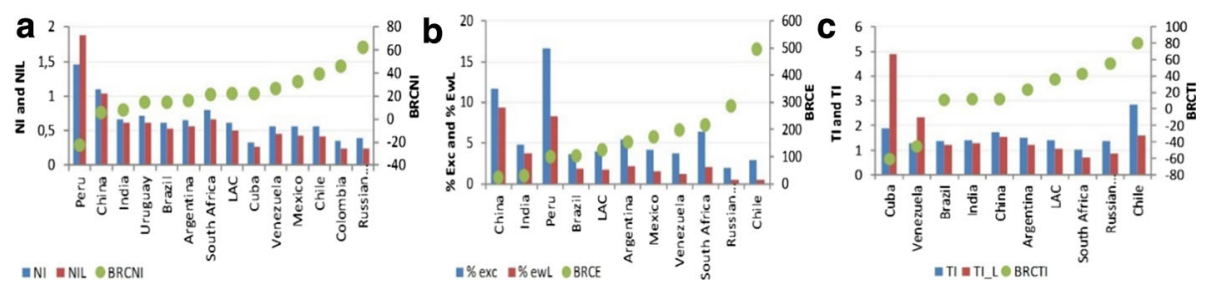

Fig. 2 Benefit rate of collaboration in normalized citation (left), scientific excellence (center) and technological impact (right) 

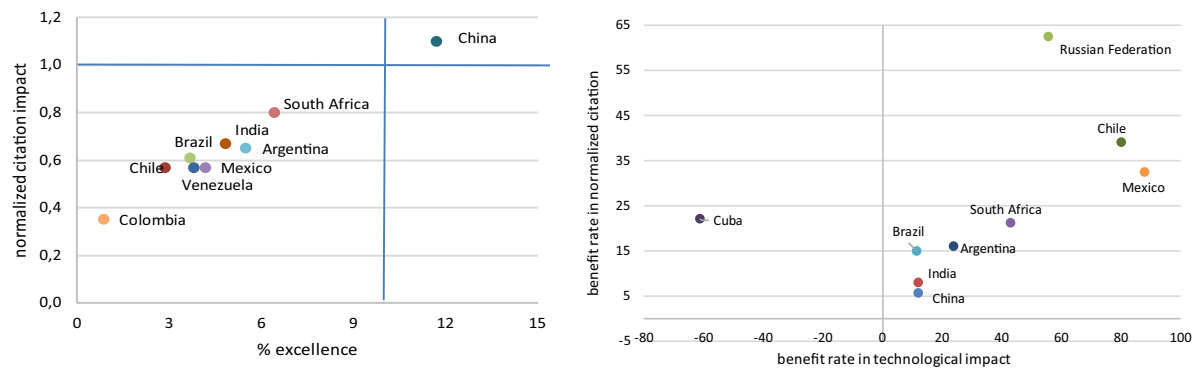

Fig. 3 Autonomy vs dependency of collaboration in scientific and technological impact

Figure 3 compares the benefits of collaboration to technological impact and normalized citation. Russia, Chile, and Mexico are relatively autonomous. Cuba leads publications cited in patents (just two papers in the period), showing a higher capacity for knowledge transfer than Colombia or Venezuela. Cuba is a particular case showing a negative benefit in technological impact, which means that the country would not need international collaboration to be autonomous. However, this finding could give rise to misinterpretations, as there are few documents cited in patents and Cuba leads international collaboration. The growth of collaboration most likely helps the country to leverage its competitiveness, taking advantage of its autonomy. If so, Cuba might reinforce this aspect in order to attract international participation and increase its potential.

Figure 4 illustrates the trends behind the influence of different types of collaboration ( $x$ axis) in the normalized citation of each country ( $y$ axis). For each country, we show the evolution over time of the normalized citation by types of collaboration. Each line shows the tendency by indicating the initial year with a circle and the final one with an arrow. The dotted line located in each graph refers to the worldwide average of normalized citation.

Brazil presents a clearly growing trend in its total and leading international collaborations, yet the percentage of papers published by one single institution and in collaboration with several domestic institutions decreases. This pattern positively affects the normalized citation of the country, especially in domestic collaborative papers. Total and leading international collaboration is seen to have a positive effect on impact, yet international collaboration is the most determinant for high citation. Furthermore, output in collaboration allows Brazil to eventually obtain normalized citation indexes above the world average.

In Mexico, the panorama is quite different. There is a rising trend for the impact of output involving international collaboration, as well as national and international collaboration, though a reverse trend appears for the levels of impact of output coming from leading collaboration. Non-collaboration and its impact decrease over the period of study, while national collaboration increases, but is not accompanied by markedly higher citations.

The impact of Argentina's internationally collaborative output has increased, even though the percentages of publications has decreased considerably. There is a citation gain for leadership roles in mixed international and national collaboration, while a decrease is seen for leadership on purely international projects. Hence, the association of domestic and foreign institutions produces the most visible outcomes. Impact is on the rise across all collaboration types, with the exception of non-collaborative output, which remains below the world average throughout the period studied. 

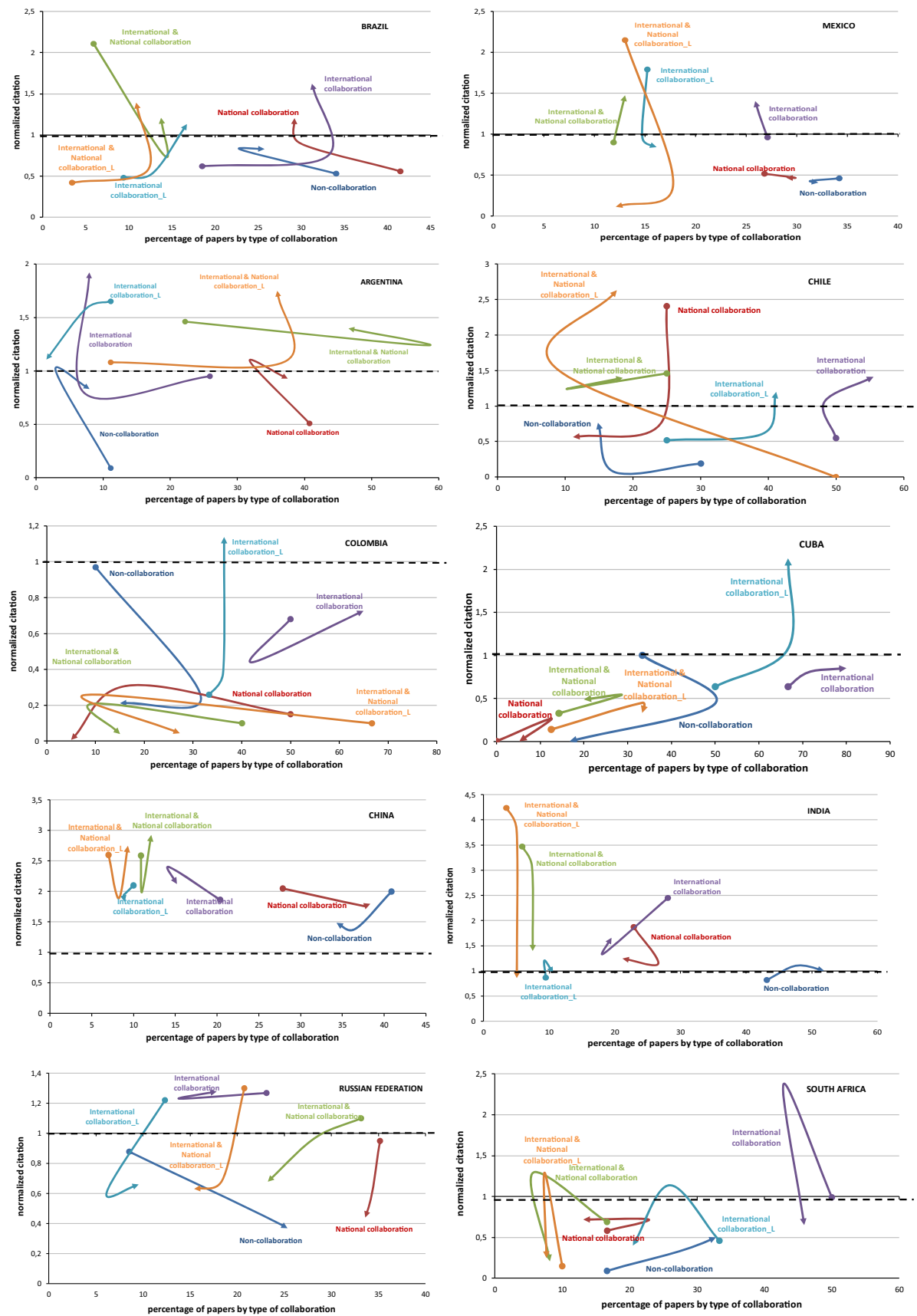

Fig. 4 Trends in collaboration and normalized citation by country 
Chile's output with all and leading international collaboration increases steadily, in both cases reaching impact values above the world mean by the end of the period analyzed. The greatest gains in impact are seen in leadership of international and national collaborations. Note that while papers and impact in national collaboration decrease, the association of national and international collaboration led by the country put Chile on the map at the international level. This pattern is relevant to orient national strategies intended to foster the visibility of Chilean research.

For Colombia, nearly all output is below the world mean at the end of the period, showing virtually no growth. Thus, this country obtained more benefits from international collaboration with leadership but did not increase its share of production. It shows no real decline in non-collaborative output, though its impact is substantially reduced. The greatest change is in the rise of impact of its leading international output, though the volume of that output has not considerably increased.

Cuba increases only its output in international collaboration, and much more in output with leadership than without leadership. This means it also considerably increases the levels of impact, which at the end of the period reach an index $>2$. Non-collaboration shows a considerable decline in both output and impact. The national and international collaboration without leadership grows slightly in volume and impact, while collaboration with leadership grows in volume but ends up with somewhat less impact.

The case of the Russian Federation is noteworthy considering that the expenditures of business enterprise, government and the higher education sector in this field are far greater than in countries such as Japan and Korea (OECD 2013). Yet all its NST output-except that entailing international collaboration-has impact levels below the world mean at the end of the period, showing virtually no percentage growth apart from leading international collaboration. Thus, this country increases considerably the number of papers published by one single institution, with a significant drop in citations respect to the world average. It shows no real decline in domestic collaborative output, though its impact is substantially reduced. The greatest change is the decrease in national and international output, with or without leadership, although in either case, the impact achieved lies below the worldwide rate.

South Africa increases only its output in non-collaborative papers with an increase in its impact that does not reach the global standard. South African output decreases in all the other types of collaboration, with a dramatic drop in citations, especially in international collaboration: at one point, it surpassed the world average, reaching 2.3 , but at the end of the period it lies at the same level of visibility as domestic collaboration.

A different pattern is observed in India, where non-collaborative papers are the most common output and surpass the world citation average at the end of the period. At the same time, national collaboration achieves high citations despite a decrease in the number of publications. The greatest decrease in the publications is found in international collaboration, yet this output is the most visible over the period. In contrast, there is a drop in visibility with respect to national and international collaboration, with or without leadership.

China is the only country where any kind of output is above the world average, despite the fact that non-collaborative and domestic papers accumulate more than half of its entire production. The trends in these two models follow different strategies-while non-collaborative papers decrease, domestic papers increase. The international collaboration also suffers a drop but is accompanied by an increase in citations. At the end of the period, national and international collaboration are the best associations in terms of citations. 
Fig. 5 Benefit rate of collaboration in normalized citation (NI vs. NIL)

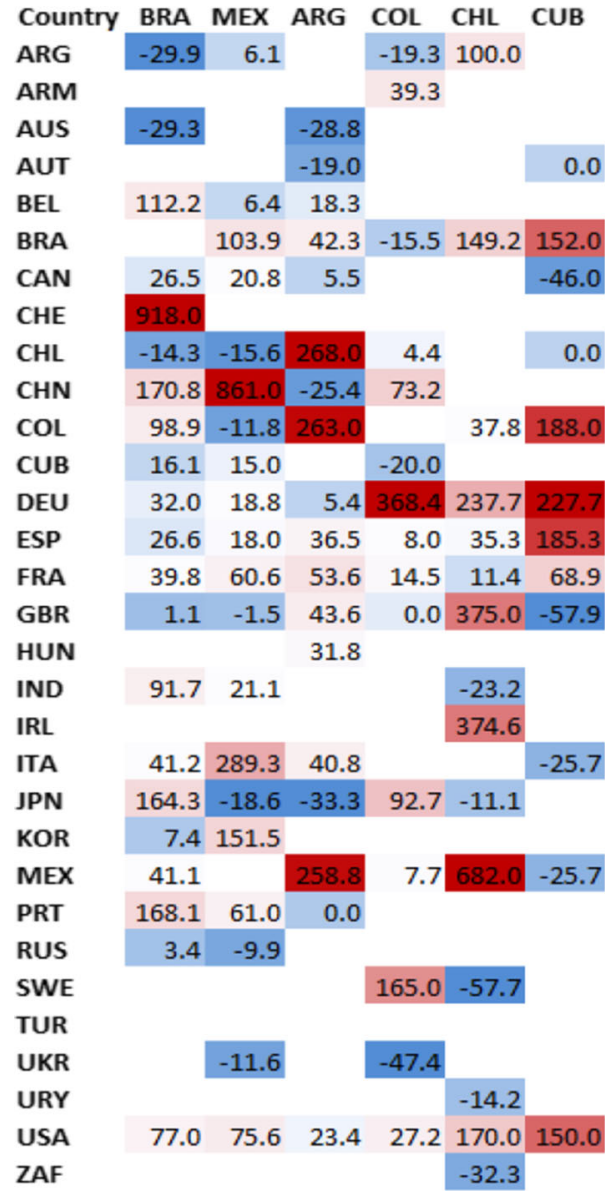

\section{A closer look at Latin America}

All relationships are not symmetrical. For a closer inspection of the benefits of particular relationships, we analyze the most frequent countries involved in collaboration and the corresponding benefit for our select group of Latin American countries (Fig. 5).

Among the collaborators, we can see the inter-regional partnership of Latin America, as well as with emergent countries. This graph offers an indication of the importance of cohesion in regional collaboration, especially in the case of Argentina, whereas the association between Brazil and the remaining emergent countries does not translate into high research performance in this field. Brazil, for instance, benefits greatly from collaboration with Switzerland, and to a lesser extent with China and India. It likewise obtains more impact when it leads research with the collaboration of Argentina and Australia.

Similarly, Mexico derives benefits from working with China, Italy, and Brazil. Argentina is a good partner for Mexico, Chile, and Colombia, who benefit as well from the impact of the output co-signed with this country. The autonomy of Argentina in obtaining a 
higher number of citations when it leads research with Austria, China and Japan, is also notable.

\section{Visualizing dependencies and autonomy: a case study of Argentina}

Visual representations are created to analyze different aspects of scientific collaboration and to identify the international facet of research by following the flow of knowledge as expressed by the number of scientific publications, and then establish the main geographical axes of output, showing the interrelationships of the domain, the intensity of these relations, and how the different types of collaboration and production are reflected in terms of visibility. Heliocentric representations show the international collaboration of Argentinean scientific output in the fields of NST as a case study. This country is more autonomous than its neighbors and shows the largest growth by leading national and international collaborations. Around the central node orbit countries with which Argentina collaborates; their relationship is represented by a line whose distance is inversely proportional to visibility/impact in terms of cites per document and the size is proportional to the percentage of collaboration with each country. The two concentric circles represent the average citation per document obtained by the total output (red) and leading output (blue), serving as a reference to highlight countries exhibiting better performance. The situation of the orbits differs from one map to the other, depending on the type of production and cites per document received. One can therefore quickly identify which countries publish more documents with Argentina (higher volume of the node) and which ones make the country more visible (the ones closest to the central node) (Chinchilla-Rodríguez 2005; ChinchillaRodríguez et al. 2010).

The maps lead us to a notable finding: although international collaboration in effect increases impact, there are different underlying reasons. Figure 6 shows international collaboration in all outputs and how collaborative countries such as Nigeria, Israel, Costa Rica, and Oman have global impact values lower than those obtained through leading documents. However, if we look at the results according to the excellence output (Fig. 7), we perceive only the role played by each country and how the patterns of production differ in terms of impact (position of the orbits and number of countries). A combined reading of the data (Figs. 8, 9) shows Argentina to have relatively poor results in terms of visibility with regard to Canada and South Korea (outside orbit blue). When Argentina leads international collaboration, India, Cuba, Mexico and Colombia are countries with which visibility is scanty; and even if the country takes the leading role in highly cited documents, collaborating countries such as Switzerland, France or Chile do not surpass the average citation of the total output. In the four representations, the countries located in the red orbit are the most highly cited and put Argentinean research on the map of excellence, achieving the highest visibility and international impact.

The fact that we can position each country in terms of output and benefits of impact makes heliocentric networks of international collaboration a complementary tool for bibliometric analysis, useful for decision-making as well. This depiction can be used for the static description or the dynamic representation of the domain. The evolutionary analysis of these relationships gives information about countries' research stability and their capacity for expansion and visibility. Thus, the results of joint projects or strategic alliances can be monitored. 


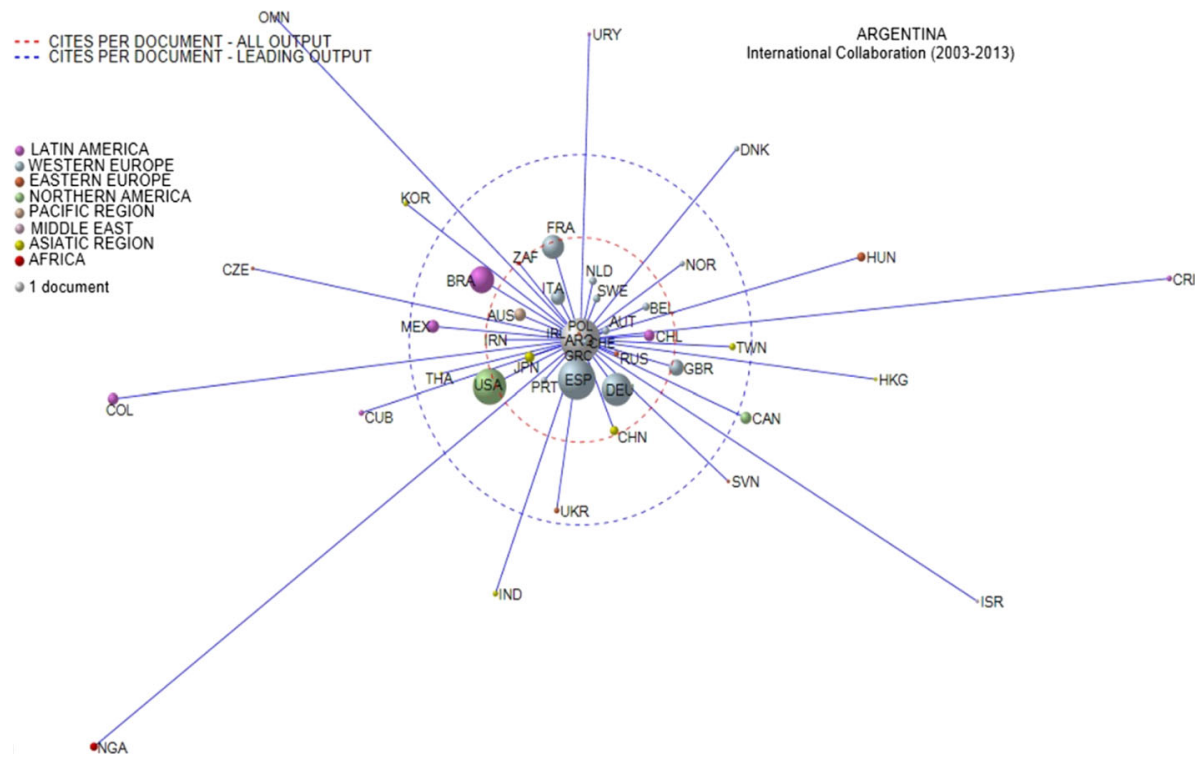

Fig. 6 Heliocentric network of international collaboration in all output

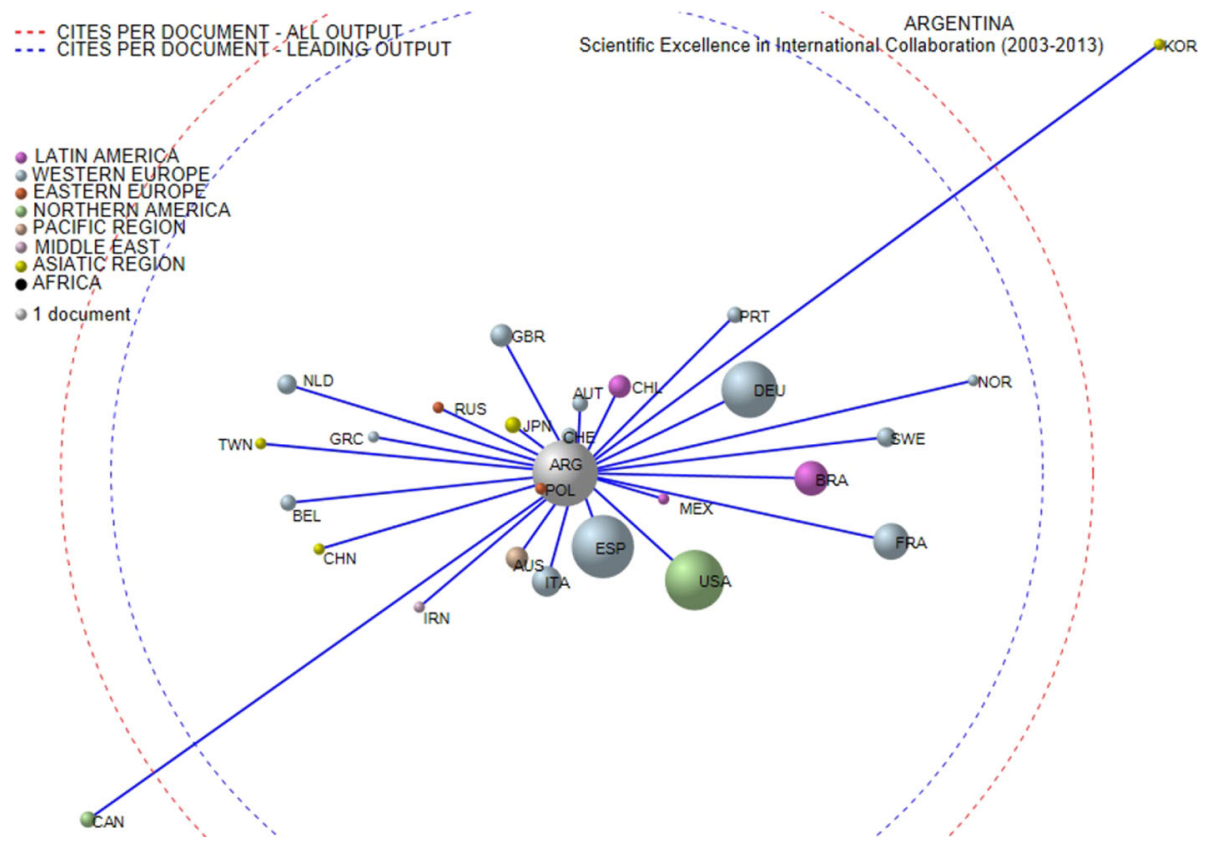

Fig. 7 Heliocentric network of international collaboration in excellence output 


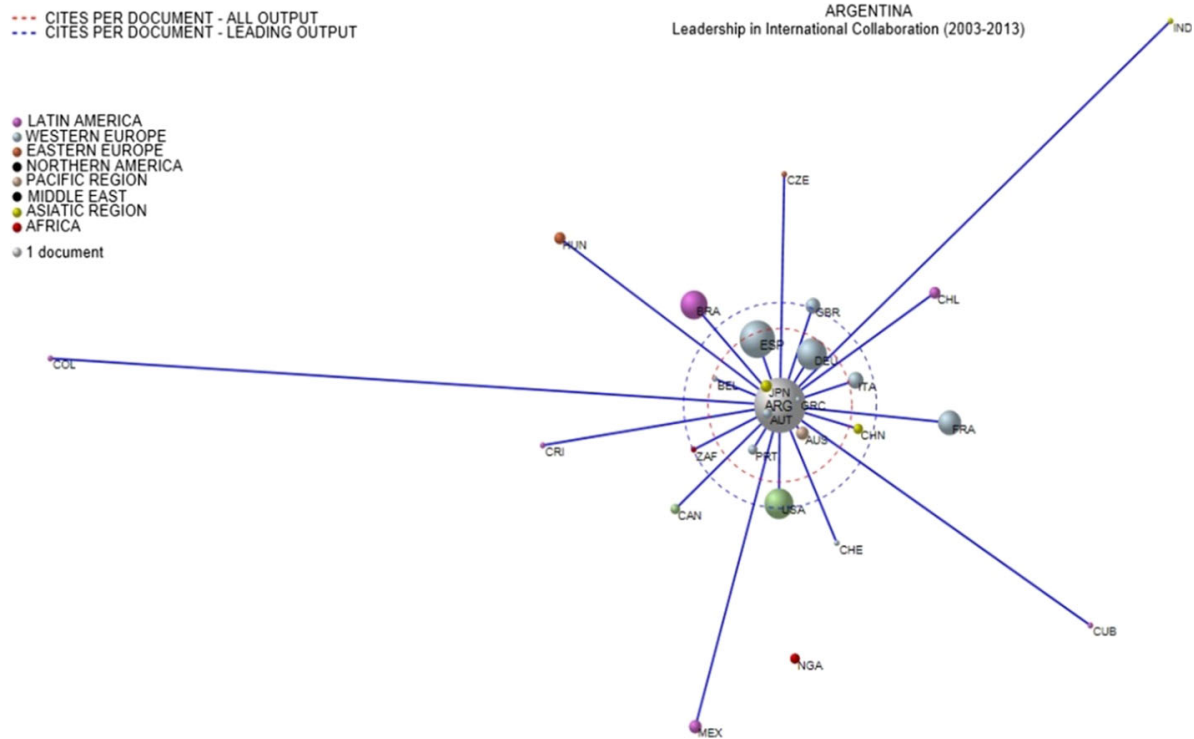

Fig. 8 Heliocentric network of international collaboration in leading output

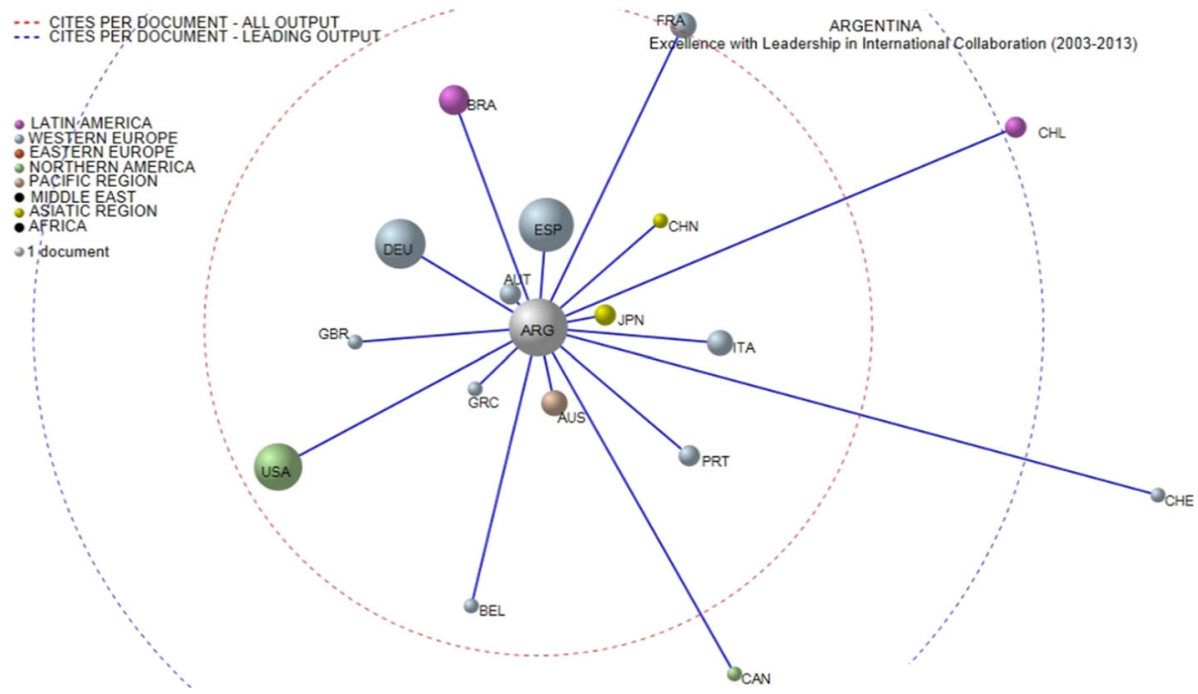

Fig. 9 Heliocentric network of international collaboration in excellence with leadership output

\section{Limitations and further research}

Some limitations of the present study should be mentioned, some of which motivate additional indicator construction. It is acknowledged that the metrics provided here are not the only indicators that might account for research performance. There are many ways to expand upon this analysis to enrich and complement the findings expounded here. As 
strongly advocated in the Leiden manifesto, scholarly metrics should play the supporting role to qualitative and in-depth analyses of scholarly content and activities (Hicks et al. 2015). For example, in future efforts, we will apply different indices to analyze asymmetries in scientific collaboration beyond the simple computation of percentages. A second problem lies in the interpretation of benefit rates for each indicator. The rule is: the lesser the benefit, the more autonomous the country. However, we must bear in mind the values of worldwide reference in normalized citation impact (1) and in top highly cited publications (10). Therefore, the autonomy or dependency of a country will depend on a low benefit rate and the fact that the country can surpass these reference levels. These conditions could act as a proof of the visibility and repercussion of their research at the international level. Further work is needed to refine indicators and interpretations. A third and final point of contention is that the selection of bibliometric indicators might ideally be complemented with another kind of indicator and/or approach, such as socio-economic and structural indicators in conjunction with the policies and programs to develop science and technology strategies on a national scale. We hold it to be of great interest, for example, to analyze the migration of scientists to appraise to what extent countries can be influenced by foreign scientists in their research performance.

\section{Conclusions}

Emerging countries play an important role in the production of research in nanoscience and nanotechnology. In fact, BRICS countries produce more in the aggregate than US production in this area. This demonstrates the importance of examining the roles of developing and emerging countries in knowledge generation. However, countries vary in the impact of their output, particularly when collaboration and leadership roles are analyzed.

South Africa has the highest international leadership, followed by Russia and Brazil; Cuba, Colombia, Venezuela and Argentina are able to lead a significant proportion of research, notwithstanding differences in their performance. Much output is seen to be exclusively carried out domestically and such non-collaborative endeavors have repercussions for the impact of research. Leadership is both a responsibility and an advantage: it is the responsibility for a publication, but also serves to increase the citation potential in terms of international collaborations. Leadership and international collaboration patterns help to characterize how research is carried out, accounting for scientific capacities within linkage networks and gauging to what extent countries play different roles in the management of their own capacities to generate knowledge and to attract international partners (Chinchilla-Rodríguez et al. 2016a, b). Leadership focused on national-oriented research where domestic institutions play a key role in producing quality research is the case in China and India, meaning that these countries show genuine capacities for autonomy, though the yield in terms of citation differs. Russia, despite a greater investment in NST, obtains little impact. The results on Russia are consistent with previous research on nanoscience (Terekhov 2017) and Russian scientific dependencies (Karaulova et al. 2016).

As for the different strategies of scientific collaboration, one notable result in the four main producers of NST in Latin America deserves mention here: the association of national and international institutions is quite beneficial. This pattern is also reflected in leading publications, yet to a lesser extent. As might be expected, the low impact of output authored by a single institution remains steady. The greatest differences appear in 
publications with international collaboration. The results show that Latin American countries are more likely to collaborate with the most consolidated countries contributing to good research performance, especially in the case of Brazil and Argentina. Simultaneously, we observe an important proportion of domestic and regional collaboration among them. Previous studies focused on the area of Medicine described cohesive inter-regional growth in Latin American research. Yet other studies reveal that the strength of the interBRICS collaboration network is very weak among the five countries that tend to collaborate with scientifically advanced countries (Finardi and Buratti 2016). Each model of collaboration (more national or international-oriented) achieves different results, but as a common denominator, collaboration with scientifically advanced countries helps visibility. This is one reason why the growth of international collaboration with or without leadership, should be interpreted as a positive aspect. The repercussion of such research can propel genuine capacities for the definition of research agendas concerned with local needs or topics of interest that would likewise be of interest to further communities abroad, in turn contributing to the development of science at a national level.

Visual representations help to identify the international facet of research by following the flow of knowledge as expressed by the number of publications, and then establishes the main geographical axes of output, showing the interrelationships of the domain, the intensity of these relations, and how the different types of production are reflected in terms of visibility. These representations lead us to a noteworthy finding: although international collaboration increases impact, not all countries are contributing to the same degree, as can be observed in the case of Argentina. The availability of this kind of information could be useful when governments design their strategic plans for science and technology in key areas, such as NST. Knowing the relative strengths and weaknesses of partners, in terms of performance and results, may help to encourage strategic associations to plan long-term projects that focus on national and international interests.

Against this research backdrop and from a perspective aligned with science policy, analysis of collaboration is justified as a way to strike an approximate balance between what is expected and what is obtained, between the effects of programs and measures, and their implementation over time. These considerations have important implications for the governance of science. Collaboration for mutual benefit and excellence is gaining acceptance, with "partner" selection becoming a strategic priority to enhance one's own production. In this context, a key prerequisite for the design of regional collaboration policies is the determination of how partners attain higher research potential. Such analyses furnish useful information for decision makers with respect to areas such as avant-garde research-like NST-with profound implications and expectations for the economic development of countries, the formation of research teams, mobility program planning, and strategic alliances regarding future collaboration. It also contributes to avoiding the duplication of effort by maximizing both human and material resources, among many other advantages (Chinchilla-Rodríguez et al. 2010).

Acknowledgements This work was financing by the Project NANOMETRICS (Ref. CSO2014-57770-R) supported by the Ministerio de Economía y Competitividad of Spain and from Mobility Program 'Salvador de Madariaga' funded by the Ministry of Economy and Competitiveness of Spain. Preliminary results of this paper were presented at the 21st International Conference on Science and Technology Indicators (STI 2016), and at the 14th International Congress of Information, (Info '2016). The comments received in both events helped us to improve the study. 
Open Access This article is distributed under the terms of the Creative Commons Attribution 4.0 International License (http://creativecommons.org/licenses/by/4.0/), which permits unrestricted use, distribution, and reproduction in any medium, provided you give appropriate credit to the original author(s) and the source, provide a link to the Creative Commons license, and indicate if changes were made.

Funding This work was made possible through financing by the Project NANOMETRICS (Ref. CSO201457770-R) supported by the Ministerio de Economía y Competitividad of Spain, the Mobility Program 'Salvador de Madariaga 2016' supported by the Ministerio de Economía y Competitividad of Spain, and the hosting of the Indiana University, Bloomington, USA.

\section{References}

Batagelj, V., \& Mrvar, A. (1997). Program package Pajek/Pajek-XXL. Available at http://mrvar.fdv.uni-lj. si/pajek/. Accessed 1 December 2016.

Beigel, F. \& Sabea, H. (coords.). (2014). Dependencia académica y profesionalización en el sur. Perspectivas desde la periferia. Mendoza: EDIUNC; Rio de Janeiro: SEPHIS.

Bonfiglioli, A., \& Mari, E. (2000). La cooperación científico-tecnológica entre la Unión Europea y América Latina: el actual contexto internacional y el Programa Marco de la Unión Europea. REDES, 7, 183208.

Chen, H., Roco, M. C., Son, J., Jiang, S., Larson, C. A., \& Gao, Q. (2013). Global nanotechnology development from 1991 to 2012: Patents, scientific publications, and effect of NSF funding. Journal of Nanoparticles Research, 15(9), 1951. https://doi.org/10.1007/s11051-013-1951-4.

Chinchilla-Rodríguez, Z. (2005). Análisis del Dominio Científico Español: 1995-2002 (ISI, Web of Science). Ph.D. Dissertation, Universidad de Granada, Spain.

Chinchilla-Rodríguez, Z., Ocaña-Rosa, K., \& Vargas-Quesada, B. (2016a). How to combine research guarantor and collaboration patterns to measure scientific performance of countries in scientific fields: Nanoscience and nanotechnology as case study. Frontiers in Research Metrics and Analytics. https:// doi.org/10.3389/frma.2016.00002.

Chinchilla-Rodríguez, Z., Vargas-Quesada, B., Hassan-Montero, Y., González-Molina, A., \& Moya-Anegón, F. (2010). New approach to the visualization of international scientific collaboration. Information Visualization, 9, 277-287. https://doi.org/10.1057/ivs.2009.31.

Chinchilla-Rodríguez, Z., Zacca-González, G., Vargas-Quesada, B., \& Moya-Anegón, F. (2016b). Benchmarking scientific performance by decomposing leadership of Cuban and Latin American Institutions in Public Health. Scientometrics, 106, 1239-1264. https://doi.org/10.1007/s11192-015-1831-z.

CYTED. (2010). Ibero-American programme for science, technology and development. Retrieved from http://www.cyted.org/.

Fernandez, M. T., Gomez, I., \& Sebastian, J. (1998). Scientific cooperation of Latin-American countries through bibliometrics indicators. Interciencia, 23, 328-337.

Finardi, U., \& Buratti, A. (2016). Scientific collaboration framework of BRICS countries: An analysis of international coauthorship. Scientometrics, 109, 433-446. https://doi.org/10.1007/s11192-016-1927-0.

Foladori, G. (2006). Nanotechnology in Latin America at the crossroads. Nanotechnology Law \& Business, 3, 205-216.

Gazni, A., Sugimoto, C. R., \& Didegah, F. (2012). Mapping world scientific collaboration: Authors, institutions, and countries. Journal of the American Society for Information Science and Technology, 63 (2), 323-335. https://doi.org/10.1002/asi.21688.

Glänzel, W. (2001). National characteristics in international scientific co-authorship relations. Scientometrics, 51(1), 69-115. https://doi.org/10.1023/A:1010512628145.

Glänzel, W., \& De Lange, C. (2002). A distributional approach to multinationality measures of international scientific collaboration. Scientometrics, 54, 75-89.

Grieneisen, M. L. (2010). The proliferation of nano journals. Nature Nanotechnology, 5(12), 825. https://doi. org/10.1038/nnano.2010.216.

Guerrero-Bote, V. P., Olmeda-Gómez, C., \& Moya-Anegón, F. (2013). Quantifying the benefits of international scientific collaboration. Journal of the American Society for Information Science and Technology, 64(2), 392-404. https://doi.org/10.1002/asi.22754.

Hicks, D., Wouters, P., Waltman, L., De Rijcke, S., \& Rafols, I. (2015). Bibliometrics: The Leiden Manifesto for research metrics. Nature, 520, 429-431. https://doi.org/10.1038/520429a. 
Huang, C., Notten, A., \& Rasters, N. (2011). Nanoscience and technology publications and patents: A review of social science studies and research strategies. The Journal of Technology Transfer, 36, 145172. https://doi.org/10.1007/s10961-009-9149-8.

Karaulova, M., Gök, A., Shackleton, O., \& Shapira, P. (2016). Science system path-dependencies and their influences: Nanotechnology research in Russia. Scientometrics, 107(2), 645-670.

Katz, J. S., \& Martin, B. R. (1997). What is research collaboration. Research Policy, 26, 1-18. https://doi. org/10.1016/S0048-7333(96)00917-1.

Kay, L., \& Shapira, P. (2009). Developing nanotechnology in Latin America. Journal of Nanoparticle Research, 11, 259-278. https://doi.org/10.1007/s11051-008-9503-z.

Kay, L., \& Shapira, P. (2011). The potential of nanotechnology for equitable economic development: The case of Brazil. In Nanotechnology and the challenges of equity, equality, and development (pp. 309329). New York: Springer. https://doi.org/10.1007/978-90-481-9615-9_19.

Kreimer, P. (2000). Cultura y periferia. La ciencia en la Argentina entre siglos. En Montserrat, Marcelo, Textos, contextos e instituciones. Buenos Aires: Manantial (pp. 187-202).

Kreimer, P. (2006). ¿Dependientes o integrados? La ciencia latinoamericana y la nueva división internacional del trabajo. Nómadas, 24, 190-212.

Lariviere, V., Desrochers, N., Macaluso, B., Mongeon, P., Paul-Hus, A., \& Sugimoto, C. R. (2016). Contributorship and division of labor in knowledge production. Social Studies of Science, 46(3), 417-435.

Leydesdorff, L., Wagner, C. S., Park, H., \& Adams, J. (2013). International collaboration in science: The global map and the network. El Profesional de la Información, 22, 87-94. https://doi.org/10.3145/epi. 2013.ene.12.

Miguel, S., González, C., \& Chinchilla-Rodríguez, Z. (2015). Lo local y lo global en la producción científica argentina con visibilidad en Scopus, 2008-2012. Dimensiones nacionales e internacionales de la investigación. Información, Cultura y Sociedad, 32, 55-74.

Moya-Anegón, F., \& Chinchilla-Rodríguez, Z. (2015). Impacto tecnológico de la producción universitaria iberoamericana. En: La transferencia de la I + D, la innovación y el emprendimiento en las universidades. Educación Superior en Iberoamérica. Informe 2015. Santiago de Chile: Centro Interuniversitario de Desarrollo (pp. 83-94).

Moya-Anegón, F., Guerrero-Bote, V. P., Bornmann, L., \& Moed, H. F. (2013). The research guarantors of scientific papers and the output counting: A promising new approach. Scientometrics, 97, 421-434. https://doi.org/10.1007/s11192-013-1046-0.

Muñoz-Écija, T., Vargas-Quesada, B., Chinchilla-Rodríguez, Z., Gómez-Núñez, A.J., Moya-Anegón, F. (2013). Nanoscience and nanotechnology in Scopus: Journal identification and visualization. In: Proceedings of ISSI 2013-14th international society of scientometrics and informetrics conference. Vienna, Austria.

OECD. (2013). OECD science, technology and industry scoreboard 2013: Innovation for growth. Paris: OECD Publishing. Available at http://www.oecd.org/sti/scoreboard-2013.pdf.

Persson, O. (2010). Are the highly cited papers more international? Scientometrics, 83, 397-401. https://doi. org/10.1007/s11192-009-0007-0.

SCimago. (2007). SCImago Journal \& Country Rank. http://www.scimagojr.com.

SCImago. (2015). SCImago Institutions Rankings. http://www.scimagoir.com.

Sutz, J. (2005). Sobre agendas de investigación y universidades de desarrollo. Revista de Estudios Sociales, $22,107-115$.

Terekhov, A. (2017). Bibliometric spectroscopy of Russia's nanotechnology: 2000-2014. Scientometrics, 110(3), 1217-1242. https://doi.org/10.1007/s11192-016-2234-5.

The World Bank. (2015). New country classifications. Available at http://blogs.worldbank.org/opendata/ new-country-classifications.

Velho, L. (2002). North-south collaboration and systems of innovation. The International Journal of Technology Management and Sustainable Development, 1, 25-49.

Vessuri, H. M. C. (Ed.). (1984). Ciencia académica en la Venezuela moderna. Caracas: Fondo Editorial Acta Científica Venezolana.

Wagner, C. S., Brahmakulam, I., Jackson, B., Wong, A., \& Yoda, T. (2001). Science and technology collaboration: Building capacities in developing countries. Santa Monica, CA: RAND. 